CASE REPORT

\title{
Primary Synovial Sarcoma of Thyroid Gland: A Case Report
}

\author{
Ranjeet K Lal ${ }^{1}$, Biswajyoti Hazarika ${ }^{2}$, Manish Julaha ${ }^{3}$
}

\begin{abstract}
Aim and objective: We report a case of synovial sarcoma of the thyroid gland and review the literature of few such reported cases. Background: Synovial sarcoma of the thyroid gland is exceedingly rare with aggressive features and very poor prognosis.

Case description: We report a case of 65-year-old man from Iraq who presented initially with a neck mass and was operated at the local hospital for total thyroidectomy, and a separate neck mass extending from the thyroid gland to the upper mediastinum was found. A re-excision of the mass was done with HPE showing malignant peripheral nerve sheath tumor. He was referred to our institute with relapse of the neck mass with compressive symptoms. The mass was excised with the HPE and IHC staining showing grade 2 biphasic synovial sarcoma. Within twenty days of surgery, he presented with severe respiratory distress and tumor with intraluminal tracheal growth. He died of compressive symptoms two weeks after the relapse.
\end{abstract}

Conclusion: The early diagnosis and margin-free resection give the best chance of survival for the patient.

Keywords: Diagnosis, Prognosis, Synovial sarcoma, Thyroid gland.

Otorhinolaryngology Clinics: An International Journal (2020): 10.5005/jp-journals-10003-1350

\section{BACKGROUND}

Synovial sarcoma is a mesenchymal spindle cell tumor. It shows a variable epithelial differentiation including glandular formation and has a specific chromosomal translocation $t$ ( $x: 18)$ (p11:q11). ${ }^{1}$ It accounts for $5-10 \%$ of all soft tissue sarcomas. The head and neck synovial sarcoma is very rare and accounts for approximately $5 \%$ of all cases. ${ }^{2}$ The occurrence of synovial sarcoma in unusual sites makes the differential diagnosis more difficult. They also exhibit aggressive features like local invasiveness and distant metastasis in such scenario. Age of incidence varies from birth to the maximum age of 89 years. The tumor is of unknown histogenesis and is unrelated to synovium. ${ }^{3}$ It commonly arises from the deep soft tissue of extremities. Four morphological variants are found, i.e., classic biphasic type, monophasic fibrous type, monophasic epithelial type, and poorly differentiated (round cell type). The initial management is the cornerstone for good prognosis; otherwise, it leads to early or late recurrence. ${ }^{4}$ In the present study, we present a case of primary synovial sarcoma with repeated local relapses and review the literature of other few recently reported cases to help us understand the disease course and its initial management and overall prognosis.

\section{Case Description}

The patient was a 65 -year-old man from Iraq with pleasant personality. He was a known diabetic and hypertensive. He presented with the history of midline neck swelling for two months to the local hospital in Iraq. On ultrasonography, a $2 \times 3 \mathrm{~cm}^{2}$ nodule with peripheral vascularity was seen in the right lobe and multiple nodules with cystic changes were seen in the left lobe. The FNAC from the left lobe nodule was suspicious for malignancy.

The patient underwent total thyroidectomy (08-11-16) intraoperatively; another mass was seen in the left side of the neck and extending from the left lobe thyroid gland to the upper mediastinum. A biopsy was taken from that mass. On histopathological examination of thyroid specimen, it revealed a multinodular colloid goiter. Biopsy from the neck mass shows ruptured epidermal inclusion cyst.
${ }^{1}$ Department of Head \& Neck Surgery, Surgical Oncology Unit-II, Artemis Hospitals, Gurugram, Haryana, India

${ }^{2,3}$ Department of Surgical Oncology, Artemis Hospitals, Gurugram, Haryana, India

Corresponding Author: Ranjeet K Lal, Department of Head \& Neck Surgery, Surgical Oncology Unit-Il, Artemis Hospitals, Gurugram, Haryana, India, Phone: +91 7399743591, +91 7002354823, e-mail: drranjeetlal@ gmail.com

How to cite this article: Lal RK, Hazarika B, Julaha M. Primary Synovial Sarcoma of Thyroid Gland: A Case Report. Int J Otorhinolaryngol Clin 2020;12(2):27-30.

Source of support: Nil

Conflict of interest: None

Re-excision of mass was done on December 4, 2016. The histopathology shows malignant peripheral nerve sheath tumor, which is of high grade with Vimentin positive.

But within three weeks of the last excision in Iraq, the patient had a relapse of the disease and was referred to our institute. On examination, there was a large, hard, and fixed neck mass in midline and left side of the neck with infected cutaneous scar overlying the mass. He also had dyspnea and dysphagia (Fig. 1). A PET CT scan was done showing a large $\left(10.1 \times 8.0 \times 16.1 \mathrm{~cm}^{3}\right)$ metabolically active lesion involving the left side of the neck with mediastinal extension, encasing trachea, abutting esophagus, prevertebral fascia, encasing the vessels, overlying skin ulcer with bland thrombus in left IJV with left cervical level $V$ nodes. No other metastatic disease was seen on PET CT. A trucut biopsy from the mass was done, and it was reported to be consistent with round cell sarcoma. In the course of two days, the patient went into severe respiratory distress, and as tracheostomy was not feasible, so it was decided to excise the neck mass.

Along with the CTVS team, the excision of the mass was done on December 26, 2016. As evident from the previous radiological scans, the mass was firm to hard, it was adherent to the strap muscles on the left side, the thyroid cartilage and cricoid cartilage; it was also encasing the trachea. It was difficult to mobilize the 


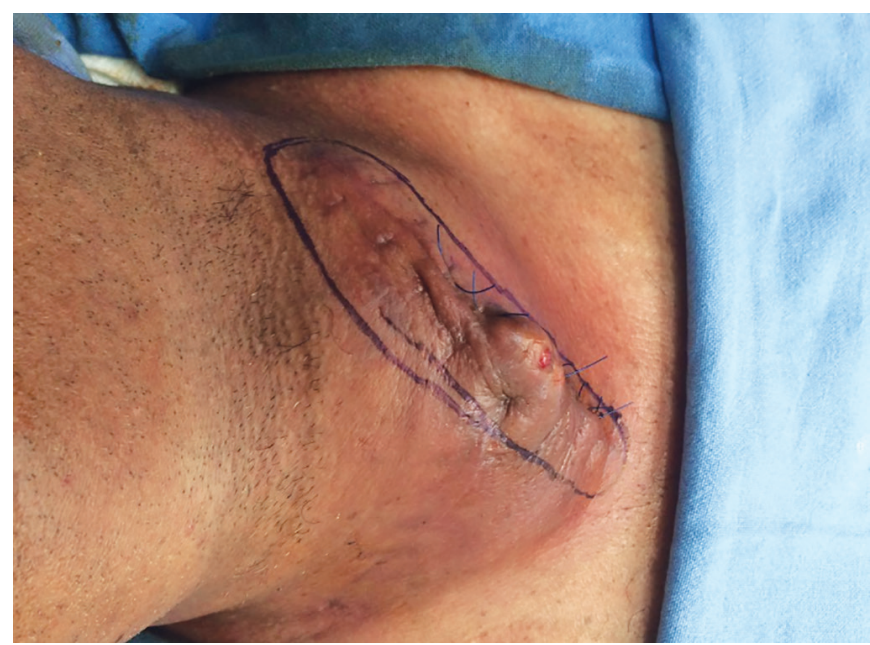

Fig. 1: Preoperative picture of the neck mass, i.e., after 1st relapse

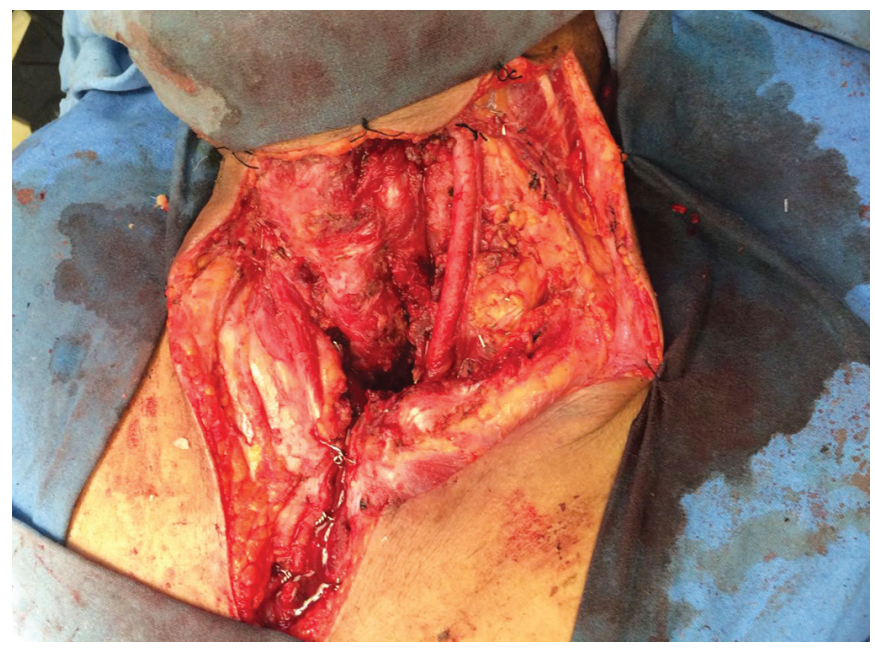

Fig. 2: Intraoperative picture after excision of the neck mass

tumor, and some parts of the tumor mass had to be excised in piecemeal. The thrombosed left IJV was removed. But both the carotids were preserved. The upper mediastinal mass was also excised, and because of the nature of dissection, we term it as R1 resection (Figs 2 and 3). The postoperative period was uneventful. He was discharged on the 7th postoperative day on January 2, 2017.

Microscopically, the tumor showed a biphasic pattern comprising predominantly of oval to spindle cells with moderate cytoplasm arranged in myxoid and collagenous background. The cells exhibit moderate nuclear pleomorphism and hyperchromasia. Epithelial differentiation was also noted within the tumor as solid nests and cords. Frequent mitosis was seen (20-25/10 HPF). The areas of coagulative necrosis $(<50 \%)$ were also seen at places (Figs 4 and 5).

The immunohistochemistry done showed that the tumor was strongly positive for Vimentin (V9), focally positive for CD99 (12 E7), bcl-2 (124), and NSE (MIG-N3). The CK (AE1+ AE3) was positive in epithelial elements only. Both the components were negative for S-100, EMA, SMA, desmin, h-caldesmon, CD34, FLI-1, and Myo-D1. The final histopathological diagnosis was biphasic synovial sarcoma (Figs 6 and 7). The patient was planned for postoperative radiotherapy and chemotherapy.
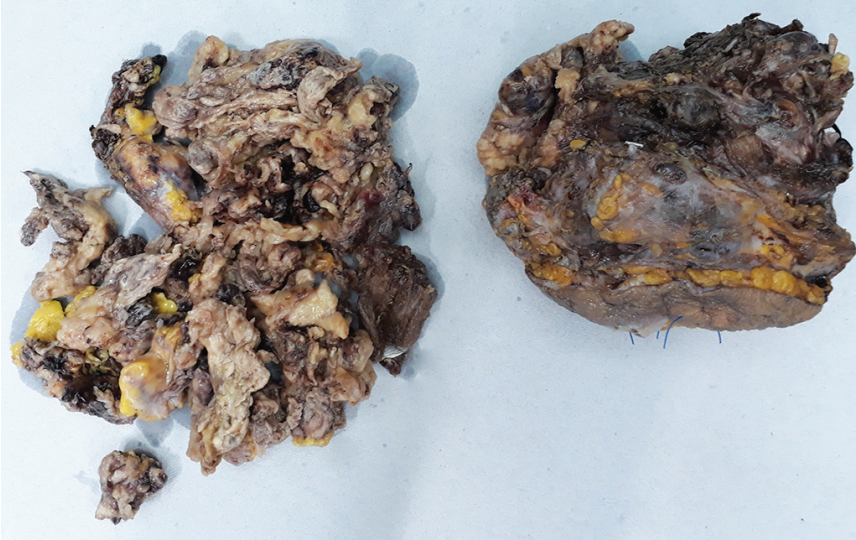

Fig. 3: Excised mass

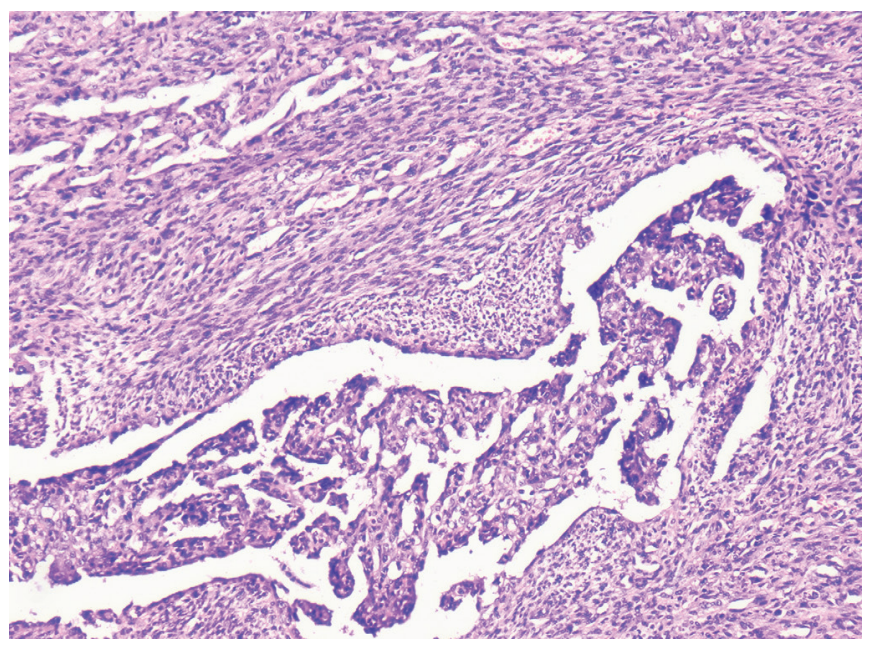

Fig. 4: Tumor showing biphasic pattern with epithelial and spindle-cell component under microscope after $\mathrm{H} \& \mathrm{E}$ staining

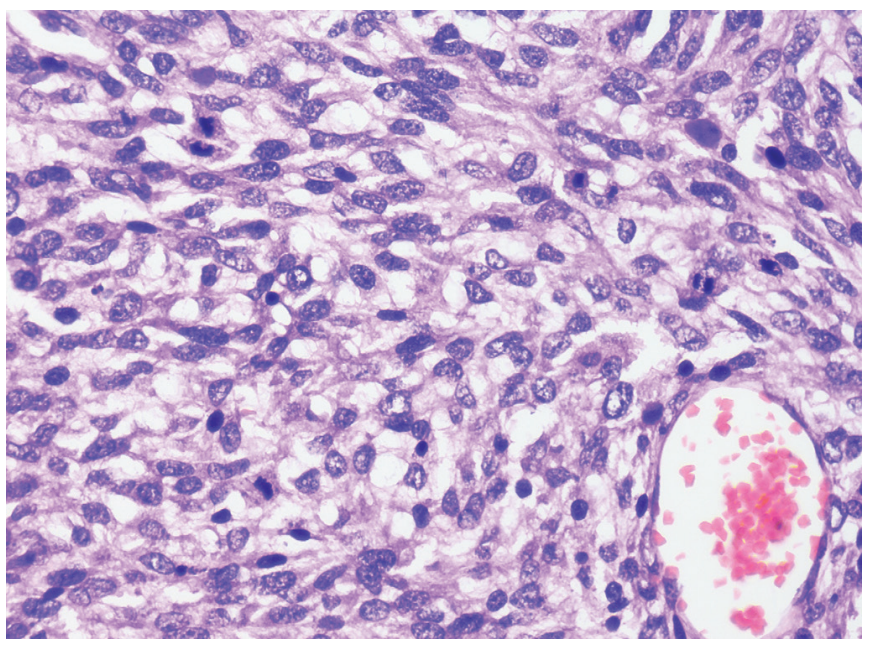

Fig. 5: Tumor showing spindle-cell component with increased mitotic rate under high resolution 


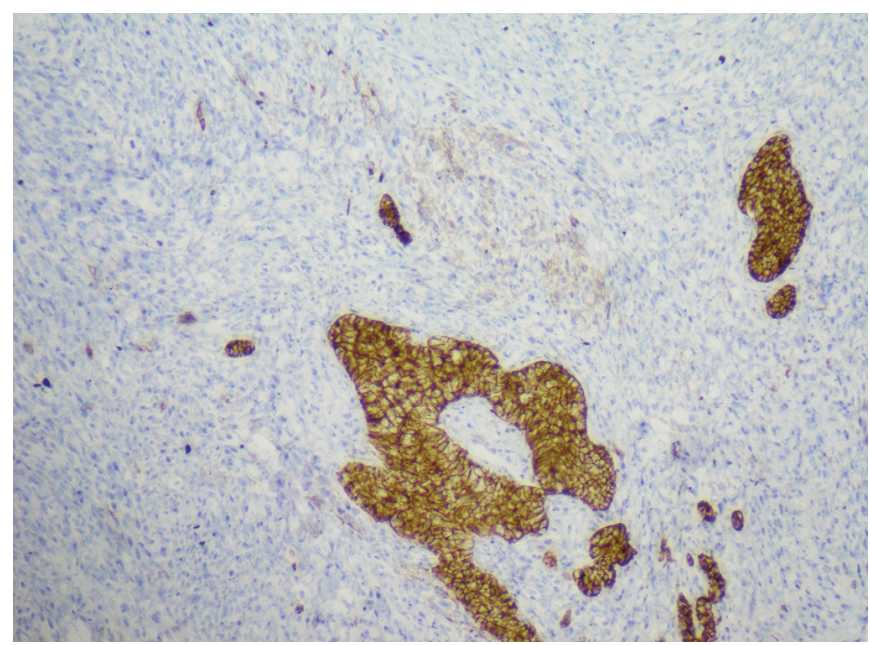

Fig. 6: Epithelial component with strong immunoexpression of pancytokeratin

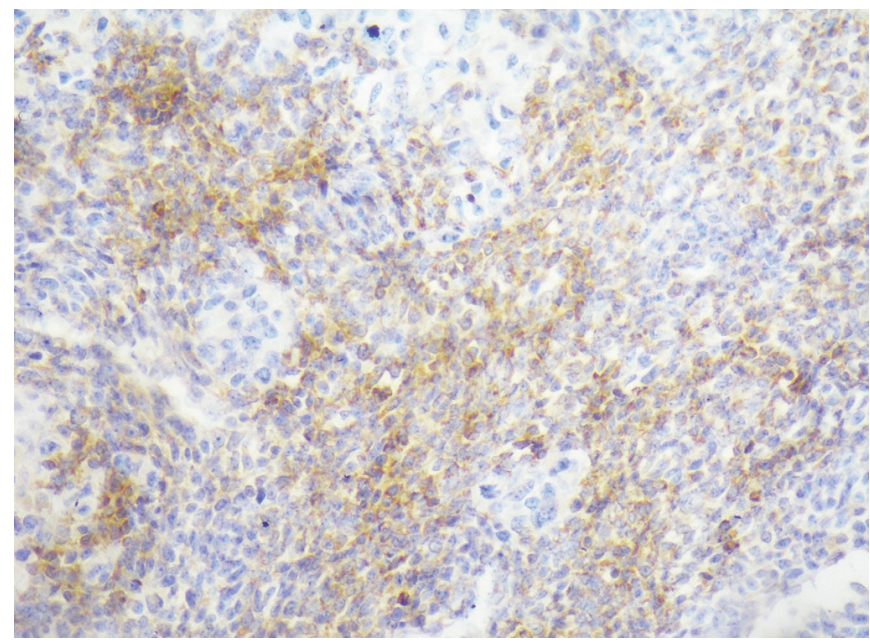

Fig. 7: Tumor showing bcl-2 immunoreactivity
But the patient again presented to us twenty days after the surgery with breathing difficulty and one episode of hemoptysis. The CT neck and chest relapse of the tumor. There was medial thyroid abutment, traversing cricoid cartilage encasing and abutting the trachea ( 270 degrees) with intraluminal soft tissue density seen protruding with the displaced tracheal lumen with posterior extension and compression of the esophagus. Multiple small discoidal nodules seen in both the lung fields which were new findings as compared to PET CT scan were done preoperatively, suggestive of local recurrence and lung metastasis.

In view of the aggressive tumor growth and intraluminal extension of mass into the tracheal lumen, the patient was planned for palliative treatment with tracheostomy for respiratory distress. The patient got himself discharged against our medical advice. The patient succumbed to his disease in his country after two weeks of discharge from our hospital.

\section{Discussion}

Thyroid sarcomas were frequently reported before the 20th century, but in 1940, Ewing reported that they were mainly anaplastic carcinoma. Since then, original primary thyroid sarcomas have been reported, including sarcoma, leiomyosarcoma, and radiationinduced sarcoma, but they are very rare in incidence. ${ }^{10}$ Few of the recent cases are summarized in Table $1 .^{5-9}$ On the evaluation of these cases including our case, we see that the median age of presentation at the time of diagnosis is 49.5 years (15-72 years), which is older than the median age reported in other locations. The main initial symptom is rapidly growing neck mass, and some of the cases also reported with dysphagia, ${ }^{6,8}$ dyspnea, ${ }^{7}$ and hoarseness. ${ }^{8}$ In almost all cases including our case, there were no history of anorexia, loss of weight, or thyroid dysfunction.

The preoperative diagnosis of primary synovial sarcoma is difficult. In all the cases, the initial radiological tool was ultrasonography of the neck. It gave fair idea about the size and location of the tumor. Most of the tumors were heterogeneous nodules with hypervascularization. CT scan and MRI of the neck and whole body scan aid in the evaluation of primary tumor and distant metastasis if any, before any operative intervention. The preoperative

Table 1: Few of the reported cases of primary synovial sarcoma of the thyroid gland in the last few years

\begin{tabular}{|c|c|c|c|c|c|c|c|c|c|c|}
\hline $\begin{array}{l}\text { S. } \\
\text { No. }\end{array}$ & $\begin{array}{l}\text { Ref No./ } \\
\text { author }\end{array}$ & $\begin{array}{l}\text { Age/ } \\
\text { sex }\end{array}$ & $\begin{array}{l}\text { Initial } \\
\text { symptoms }\end{array}$ & $\begin{array}{l}\text { Preoperative } \\
\text { diagnosis }\end{array}$ & $\begin{array}{l}\text { Initial } \\
\text { treatment }\end{array}$ & $\begin{array}{l}\text { Pathological } \\
\text { tumor size, } \\
\mathrm{cm} / \text { margins }\end{array}$ & $\begin{array}{l}\text { Monophasic } \\
\text { or biphasic }\end{array}$ & $\begin{array}{l}\text { Adjuvant } \\
\text { treatment }\end{array}$ & $\begin{array}{l}\text { Relapse (months } \\
\text { after surgery) }\end{array}$ & $\begin{array}{l}\text { Last follow-up } \\
\text { (months after } \\
\text { surgery) }\end{array}$ \\
\hline 1 & $\begin{array}{l}\text { Shi et al. } \\
(2016)^{5}\end{array}$ & $31 / \mathrm{m}$ & Neck mass & No & Surgery & $\mathrm{R} 2$ & Biphasic & No & $\begin{array}{l}\text { 1st lo- } \\
\text { cal/24months } \\
\text { 2nd local/10 } \\
\text { months after 1st }\end{array}$ & NA \\
\hline 2 & $\begin{array}{l}\text { Boudin } \\
\text { et al. }(2014)^{6}\end{array}$ & $55 / \mathrm{m}$ & $\begin{array}{l}\text { Neck mass/ } \\
\text { dysphagia }\end{array}$ & No & Surgery & $7 \mathrm{~cm} / \mathrm{R} 2$ & Monophasic & No & $\begin{array}{l}\text { Local ( } 0.5 \\
\text { months) }\end{array}$ & NA \\
\hline 3 & $\begin{array}{l}\text { Gafouri } \\
\text { et al. }(2013)^{7}\end{array}$ & $44 / f$ & $\begin{array}{l}\text { Neck mass/ } \\
\text { dyspnea }\end{array}$ & No & Surgery & $\sim 15 \mathrm{~cm} / \mathrm{R} 2$ & - & No & - & - \\
\hline 4 & $\begin{array}{l}\text { Ryu et al. } \\
(2011)^{8}\end{array}$ & $72 / f$ & $\begin{array}{l}\text { Neck mass/ } \\
\text { hoarseness/ } \\
\text { dysphagia }\end{array}$ & No, FNAB & Surgery & $6 \mathrm{~cm} / \mathrm{R} 2$ & Monophasic & No & $\begin{array}{l}\text { Local and lung } \\
\text { ( } 0.5 \text { months) }\end{array}$ & $\begin{array}{l}\text { Dead of un- } \\
\text { known cause ( } 3 \\
\text { months ) }\end{array}$ \\
\hline 5 & $\begin{array}{l}\text { Jang et al. } \\
(2007)^{9}\end{array}$ & $15 / \mathrm{m}$ & Neck mass & No, FNAB & Surgery & $6 \mathrm{~cm} / \mathrm{R} 0$ & Biphasic & No & - & - \\
\hline 6 & Our case & $65 / \mathrm{m}$ & Neck mass & No, FNAB & Surgery & $10 \mathrm{~cm} / \mathrm{R} 1$ & Biphasic & No & $\begin{array}{l}\text { Local and lung } \\
\text { (0.5 months) }\end{array}$ & $\begin{array}{l}\text { Dead of disease } \\
1.5 \text { months of } \\
\text { revision surgery }\end{array}$ \\
\hline
\end{tabular}


FNA as seen by case reported by Ryu et al. and Jang et al. does not aid in the diagnosis of synovial sarcoma of the thyroid. In our case, FNA was reported to be hemorrhagic colloid nodule (right lobe) and 15 to $30 \%$ cells suspicious of malignancy (left lobe). Thus, we can conclude that until a preoperative incisional biopsy/trucut biopsy is taken, it is very difficult to ascertain the diagnosis of primary synovial sarcoma of the thyroid with the help of FNAC or radiological investigations.

Synovial sarcomas are morphologically biphasic or monophasic. The histologic hallmark of biphasic synovial sarcoma is dual lines of differentiation (i.e., epithelial-like and mesenchymal-like). ${ }^{11}$ Many synovial sarcomas are monophasic, being composed of only spindled cells or, very rarely, epithelial cells. ${ }^{11}$ Lesions composed solely of spindled cells are easily mistaken for fibrosarcomas or malignant peripheral nerve sheath tumors. ${ }^{11} \mathrm{~A}$ characteristic feature when present is calcified concretions that can sometimes be detected radiographically. Immunohistochemistry is helpful in identifying these tumors, since the tumor cells yield positive reactions for keratin and epithelial membrane antigen, differentiating them from most other sarcomas. ${ }^{11}$

The final diagnosis is made by postoperative histopathology examination, immunohistochemistry staining, and molecular analysis. The HPE of postoperative specimen in our case was biphasic synovial sarcoma like two other reported cases by Shi et al. ${ }^{5}$ and Jang et al. ${ }^{9}$, while another two cases reported to be monophasic synovial sarcoma. The IHC staining confirmed the diagnosis in all the reported cases to be synovial sarcoma including our cases. Cytokeratin was positive for our case and for the case reported by Shi et al. ${ }^{5}$ and Jang et al. ${ }^{9}$ Vimentin was positive for our case and for the case reported by Gafouri et al. ${ }^{7}$ Additional case reported by Shi et al. ${ }^{5}$ was positive for bcl-2, and the case reported by Ryu et al. $^{8}$ was positive for CD 99 like the case reported by us. The diagnosis in doubtful cases like monophasic SS can be confirmed by molecular analysis, detecting SYT-SSX gene fusion by real-time reverse transcriptase polymerase chain reaction (RT-PCR) or FISH. ${ }^{12}$

There are very limited resources available to guide us in the treatment of this aggressive disease with very poor prognosis. But it is evident from the available data that like any other soft tissue sarcoma, margin-free resection of the tumor is the cornerstone of good outcome of primary synovial sarcoma of the thyroid. Unfortunately because of the large size of tumor and proximity and invasion of vital structures of the neck $\mathrm{k}^{5-8}$, it is very difficult to achieve a margin-free (R0) resection intraoperatively.

It should be followed by adjuvant radiotherapy. The role of neoadjuvant and adjuvant chemotherapy is indeterminate as stated in a retrospective study by Italiono et al. of 237 cases of localized synovial sarcoma recorded in the database of French sarcoma group. ${ }^{13}$

But in the recently reported two cases of Shi et al. and Boudin et al. ${ }^{5,6}$ of primary SS of the thyroid gland, the chemotherapy was used after the 1st relapse of the disease. It was found to be chemosensitive of indeterminate nature and helped to reduce or delay the relapse and may reduce the tumor size for a favorable resection.

In our present case, we had planned for postoperative chemotherapy and radiotherapy but the patient had a very early and fatal relapse and the patient did not survive for the treatment.

\section{Conclusion}

The diagnosis of the reported patient could not be arrived at during initial management. A proper preoperative diagnosis is essential for proper management, and preoperative biopsy could have guided us in that direction. After the 1st excision of the neck mass, adjuvant radiotherapy could have delayed the early local relapse. He presented to us with extensive local recurrence, and even after we did a surgical resection, he had a fatal and early 2 nd local recurrence and distant metastasis to the lungs.

\section{Clinical Significance}

The primary synovial sarcoma of the thyroid gland is very rare and carries very poor prognosis. The preoperative diagnosis is difficult. So primary synovial sarcoma of the thyroid should be kept in the differential diagnosis of rapidly growing anterior neck mass. The postoperative histopathology, immunohistochemistry, and molecular analysis confirm the diagnosis. Early diagnosis and margin-free resection of tumor mass are the cornerstones of good management and favorable outcome. It should be followed by adjuvant radiotherapy. The role of chemotherapy needs to be evaluated further. Thus, we should report more of such cases, which can help to define the proper management of primary synovial sarcoma.

\section{References}

1. Fisher C, De Bruijn DRH, Geurts Van kessel A, et al. Lyon: IARC Press; 2002. Tumors of uncertain differentiation. In Pathology and Genetics of Tumors of Soft Tissue and Bone. World Health Organization classification of Tumors; pp. 200-204.

2. Al-Daraji W, Lasota J, Foss R, et al. Synovial sarcoma involving the head: Analysis of 36 cases with predilection to the parotid and temporal regions. Am J Surg Pathol 2009;33(10):1494-1503.

3. Enzinger FM, Weiss SE. Synovial sarcoma. In: Enzinger FM, Weiss SE, editors. Soft tissue tumors. 4th ed. St Louis: C.V. Mosby; 2006. pp. 1483-1502.

4. Sultan I, Rodriguez-Galindo C, Saab R, et al. Comparing children and adults with synovial sarcoma in the surveillance, epidemiology, and end results program, 1983 to 2005: an analysis of 1268 patients. Cancer 2009;115:3537-3547. DOI: 10.1002/cncr.24424.

5. Shi RL, Qu N, Gao LL, et al. Primary synovial sarcoma of the thyroid with locally repeated relapses in short periods: a case report. Biomed Rep 2016;5:79-82.

6. Boudin L, Fakhry N, Chetaille B, et al. Primary synovial sarcoma of thyroid gland: case report and review of literature. Case Rep Oncol 2014;7(1):6-13. DOI: 10.1159/000357913.

7. Ghafouri A, Anbara T, Mir A, et al. Thyroid synovial sarcoma: a case report. Acta Med Iran 2013;51(1):69-72.

8. Ryu CH, Cho KJ, Choi SH. Synovial sarcoma of the thyroid gland. Clin Exp Otorhinolaryngol 2011;4(4):204-206. DOI: 10.3342/ ceo.2011.4.4.204.

9. Jang KS, Min KW, Jang SH, et al. Primary synovial sarcoma of the thyroid gland. J Korean Med Sci 2007;22(Suppl):S154-S158. DOI: 10.3346/jkms.2007.22.S.S154.

10. Winship T, Greene R. Reticulum cell sarcoma of the thyroid gland. Br J Cancer 1955;9(3):401-408. DOI: 10.1038/bjc.1955.38.

11. Kumar V, Abbas A, Fausto N, et al. Robbins and Cotran pathologic basis of disease. - 9th ed. with illustrations by James A. Perkins. Philadelphia: Saunders; 2015. p. 1223.

12. Thway K, Fisher C. Synovial sarcoma: defining features and diagnostic evolution. Ann Diagn Pathol 2014;18(6): 369-380. DOI: 10.1016/j. anndiagpath.2014.09.002.

13. Italiano A, Penel N, Robin YM, et al. Neo/adjuvant chemotherapy does not improve outcome in resected primary synovial sarcoma: a study of the French Sarcoma Group. Ann Oncol 2009;20(3):425-430. DOI: 10.1093/annonc/mdn678. 